\title{
Mechanism of Organic Odor Generation from Thermophilically Digested Biosolids
}

\author{
Jongmin Kim \\ Civil Engineering Department, University of Texas Rio Grande Valley, TX, USA \\ Department: Civil and Environmental Engineering, Virginia Polytechnic Institute and State University, VA, USA \\ Corresponding author email: Jongmin.kim@utrgv.edu
}

Received: 07 July 2020 / Revised: 30 August 2020 / Accepted: 01 September 2020 / Published: 04 September 2020

\begin{abstract}
In anticipation to generate more stabilized biosolids, thermophilic anaerobic digestion systems are widely used to destroy greater sludge organics thus making them less odorous. In this study, singlestage thermophilic (at $55^{\circ} \mathrm{C}$ ) and mesophilic (at $37^{\circ} \mathrm{C}$ ) anaerobic digesters were studied to compare organic removal efficiencies and sulfur-based odor generation from their biosolids. Although the thermophilic system removed about 9\% more volatile solids than the mesophilic system, about 55 times more odorous organic sulfur compounds were measured from dewatered thermophilic biosolids. Different methanogenic species were found to be responsible for malodorous dewatered biosolids from the thermophilic anaerobic digester.
\end{abstract}

Keywords: Anaerobic digestion, Solid reduction, Organic odor

\section{Introduction}

The anaerobic digestion system is one of the most widely used wastewater sludge treatment technologies that relies on microbes to convert organic contaminants to carbon dioxide, methane, and stabilized residue (biosolids) without oxygen. The final products of the anaerobic system including methane and biosolids are currently viewed as renewable commodities in the world. Usual anaerobic digestion happens in the human body temperature at $37{ }^{\circ} \mathrm{C}$, also called mesophilic temperature while the anaerobic system operated at a much higher temperature of $55{ }^{\circ} \mathrm{C}$ (thermophilic) has gained popularity lately.

One of the challenging problems associated with the anaerobic digestion system is sludge odors after digestion and dewatering processes. Recent research also concluded that aged, dewatered biosolids cakes were still a significant source of sludge odors [1]. It is widely agreed that odors from anaerobically digested and dewatered biosolids consist mainly of volatile organic sulfur compounds (VOSCs) [1, 2, 3, 4]. Major components of biosolids VOSCs are methanethiol (MT) and dimethyl sulfide (DMS). As described by Higgins et al. [3], organic sulfur compounds from dewatered biosolids can be generated by the degradation of sulfur-containing amino acids and methylation of sulfide and MT to MT and DMS, respectively.

In a review of updated sludge odor reduction technologies [5], authors claimed that the combination of physical, chemical, and biotechnological technologies has become very attractive recently. This hybrid technology was found to be highly reliable in sludge odor removal among other emerging technologies like adsorption, chemical scrubbing, biofiltration, biotrickling, bioscrubbing, and activated sludge diffusion. However, these new technologies are still not reliable due to the high price and complex operation.

If the biological sulfur odor removal mechanism in the conventional sludge stabilization technologies, mesophilic anaerobic digesters (MADs) and thermophilic anaerobic digesters 
Mechanism of Organic Odor Generation from Thermophilically Digested Biosolids

(TADs), is known, then it may be possible to mitigate the odor problems associated with digested and dewatered sludge cakes by making changes to the existing operation. Although TADs have been observed to remove more solids due to accelerated biochemical reactions and higher microbial growth rates than MADs [6], more sulfur-based sludge odors were measured from the thermophilic system than the mesophilic system [7]. In the natural system, methanogens can degrade organic sulfur compounds to hydrogen sulfide and methane [8], and the same methanogens are responsible for methane formation in the anaerobic digestion system. It may be the different composition of microbial species in different digestion conditions in TADs and MADs that cause highly odorous dewatered sludge from TADs.

In this study, two lab-scale single-stage anaerobic digestion systems (TAD and MAD) were operated to study their ability to remove organics and VOSCs. Also, the composition of archaeal species was investigated to understand about sulfur odor generation mechanism under different anaerobic digestion temperatures.

\section{Research Methodology}

\subsection{Digester Setup}

The overall digester setup is shown in Fig. 1. TAD and MAD reactors were prepared with 20L high-density polyethylene carboys (Nalgene, Rochester, New York). TAD reactor was covered with aluminum foil for protection and even heat distribution and a temperature adjustable heating tape (Model No. BSAT 101-100, Thermodyne, Dubuque, Iowa) was place on the aluminum foil. Both reactors were kept in a constant temperature room at $37^{\circ} \mathrm{C}$. The TAD system was heated to $55{ }^{\circ} \mathrm{C}$ and no additional heat was applied to the MAD system. Both reactors were mixed by a magnetic stir bar and a stirring plate (Model No. Cimarec 2, Thermolyne, Dubuque, Iowa). A gas collecting bag was installed to the top of each reactor to alleviate excess gas pressure. The solids retention time of each reactor was 24 days, which was maintained by removing half-liter biosolids from the digester and feeding the same amount of feed sludge daily.
The operational volume of both reactors was 12 L. Feed sludge was prepared by mixing sludge shipped from a wastewater treatment plant at Duluth, MN, USA with tap water to make a 3\% total solids (TS) feed. The plant did not practice primary treatments at the time of the study. Since the Duluth plant accepted wastes partially from pulp and paper manufacturing industries (about $2 / 3$ of total flow), its sludge contained high sulfur. The average sulfate concentration of the $3 \%$ TS feed sludge was $171.3 \pm 3.7 \mathrm{mg} / \mathrm{L}$ as sulfate and dissolved sulfide in the feed was 0.6 $\mathrm{mg} / \mathrm{L}$.

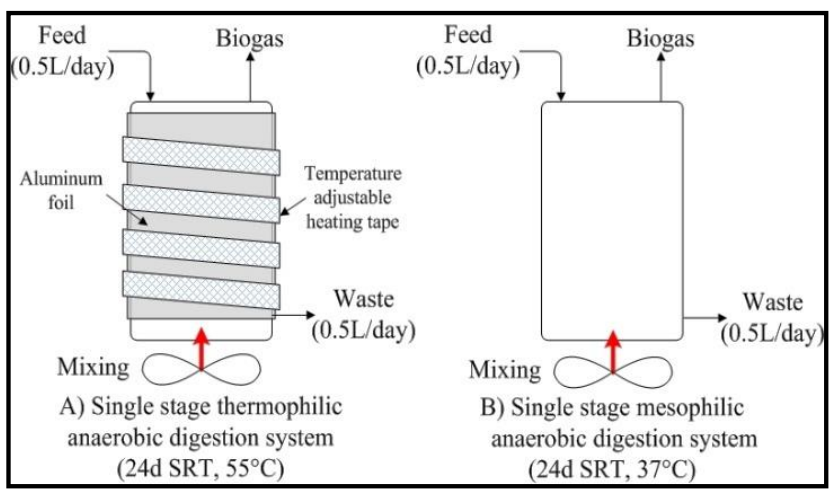

Figure 1: Digester setup

\subsection{Analysis}

The $\mathrm{pH}$ of the biosolids sample was measured by a pH probe (Model No. 13-620-287, Accumet, Petaling Jaya, Malaysia) and a $\mathrm{pH}$ meter (Model No. 910, Accumet, Cambridge, MA). Total and volatile solids (TS/VS) were measured following standard methods [9].

Biosolids dewatering was tested by the method described by Muller et al. [4]. A 1\% (w/w) highmolecular-weight cationic polymer (Clarifloc 3275, Polydyne, College Park, GA) was used as a coagulant and the dewatering time was measured by a capillary suction time (CST) apparatus (model \# W.R.C type 165, Triton Electronics Ltd., Essex, UK). Initially, a mixture of cationic polymer and 100-mL biosolids sample was sheared in a Waring laboratory blender (model \#55A60VL22, General Electronics, Fort Wayne, IN) at $2300 \mathrm{rpm}(1203 \times \mathrm{G})$ for 30 seconds. This sheared mixture was tested for CST, and the amount of cationic polymer that promoted the lowest CST was chosen as an optimum polymer dose. 
Jongmin Kim, Int. Ann. Sci.; Vol. 10, Issue 1, pp: 60-66, 2021

After the optimum polymer dose being determined, the mixture of biosolids and the optimum polymer was sheared in a Waring blender as described above, centrifuged at 10000 rpm $(17700 \times \mathrm{G})$ for 15 minutes at room temperature (approximately $22{ }^{\circ} \mathrm{C}$ ) and pressed under $207 \mathrm{kPa}(30 \mathrm{psi})$ for 15 minutes by a laboratory press. This provided a dewatered biosolids cake like ones generated by a high-solids centrifuge [4]. Approximately $25 \mathrm{~g}$ of pressed biosolids pellets were incubated in a glass bottle (250 mL, I-Chem, Rochester, NY) with Teflonlined septa for VOSC measurement. This incubation scheme was designed to simulate the storage of dewatered biosolids in a silo or a containing area where air traffic is limited so that anaerobic incubation can happen. Odorous organic sulfur compounds were measured by the method of Glindemann et al. [10]. Approximately $100 \mu \mathrm{L}$ headspace gas from each incubation bottle was collected periodically and injected into a gas chromatograph/mass spectrometer (model no. GC 6890, MSD 5970, Hewlett-Packard, Avondale, PA) with a cryo-trapping. Cryo-trap was used to accumulate gas samples and to generate narrow chromatographic peaks. A 30$\mathrm{m}$-long and 0.25 -mm-internal-diameter column (model no. 20751-01A, Supelco, Bellefonte, PA) was connected to the gas injection inlet $\left(200{ }^{\circ} \mathrm{C}\right.$ temperature), and helium was used as carrier gas (2 $\mathrm{mL} / \mathrm{min}$ ). The oven temperature was programmed to rise from 50 to $265^{\circ} \mathrm{C}$ at a rate of $35{ }^{\circ} \mathrm{C} / \mathrm{min}$. The total analysis time was 7.64 minutes. Odorous compounds that were measured in the study were hydrogen sulfide, MT, DMS, and DMDS. Peak areas of each organic sulfur compound were integrated by the data analysis program, G1034C version C.03.00 (Hewlett-Packard, PA). The amount of organic sulfur in each sample was quantified by comparing the sample peak area with the area of a standard gas mixture of a known amount of hydrogen sulfide, MT, and DMS (Scott Specialty Gases Inc., Plumsteadville, PA). The DMDS was quantified using DMS as a reference. All the biosolids odor data are presented as total VOSC (tVOSC), which is the sum of MT, DMS, and DMDS.

\subsection{Microbial Analysis}

Thermophilic biosolids were collected aseptically and centrifuged at $14,000 \times \mathrm{G}$ for 30 minutes. Total DNA extraction from $10 \mathrm{mg}$ homogenized pellet was done by FastDNA® Spin Kit for Soil (MP Biomedicals, Carlsbad, CA) following the manufacturer's protocol. The final volume of 100 $\mu l$ genomic DNA extracts was kept at $-80{ }^{\circ} \mathrm{C}$ before analysis.

Archaeal 16S rRNA gene segments were amplified from total genomic DNA extracts of the TAD biomass using the primers pARCH340F (5'-CCC TAC GGG GYG CAG G-3') [11] and ARC915R (5'-GTG CTC CCC CGC CAA TTC CT-3') [12]. Cloning was done by the Promega (Madison, WI) pGEM®-T Easy Vector system according to the manufacturer's protocol. In total, 165 genomic DNA inserts (70 from forward, 95 from reverse) were recovered from successful clones at EcoR1 restriction sites. All products were sequenced using a BigDye Terminator cycle sequencing kit (version 3.1) with an Applied Biosystems (Foster City, CA) 3730XL capillary electrophoretic DNA analyzer at the University of Minnesota DNA Sequencing and Analysis Facility. Each sequence was compared to known phylogenetic relatives from the nucleotide BLAST (BLASTn) program [13]. The sequences showing $99 \%$ or greater sequence similarity were considered as operational taxonomic units (OTUs).

\section{Results and Discussion}

\subsection{Solids Reduction}

The overall digester performance data is presented in Table 1. Both digestion systems showed stable performance throughout the study. Standard deviations of volatile solids contents and $\mathrm{pHs}$ of both systems were less than $5 \%$ of averages. System stability was evidenced by high alkalinity of greater than $5000 \mathrm{mg} / \mathrm{L}$ as $\mathrm{CaCO}_{3}$ observed throughout the study.

Volatile solids removal of the TAD system was greater than that of the MAD system by $9 \%$ and it conformed to the findings of Zahler et al. [6]. The increased kinetic reaction rate by elevated temperature enabled the TAD system to remove more sludge solids than the MAD system. 
Mechanism of Organic Odor Generation from Thermophilically Digested Biosolids

Table 1: $p H$ and solids reduction from the MAD and TAD systems

\begin{tabular}{|c|c|c|}
\hline & Thermophilic biosolids & Mesophilic biosolids \\
\hline $\mathrm{pH}$ & $8.1 \pm 0.1$ & $7.4 \pm 0.1$ \\
\hline $\mathrm{VS}(\mathrm{g} / \mathrm{L})$ & $\begin{array}{c}12.6 \pm 0.6 \\
(40.8 \pm 2.2 \% \text { removal })\end{array}$ & $\begin{array}{c}14.2 \pm 0.7 \\
(31.2 \pm 2.2 \% \text { removal })\end{array}$ \\
\hline $\begin{array}{c}\text { Alkalinity } \\
\left(\mathrm{g} / \mathrm{L} \mathrm{as}^{\mathrm{CaCO}}\right)\end{array}$ & $5.8 \pm 0.2$ & $5.4 \pm 0.2$ \\
\hline
\end{tabular}

\subsection{Dewatering Properties}

Greater solids reduction in the TAD system resulted in more solution biopolymer release in the digestion system (Table 2). A biopolymer is the sum of protein and polysaccharide. More solution protein was measured for the TAD system while both protein and polysaccharide were reduced for the MAD system. The greater amount of solution biopolymer release from the TAD necessitated a higher optimum polymer dose for dewatering processes and caused poorer dewatering, which was evidenced by a higher raw CST. Novak and Park [14] also suggested a linear correlation between the solution biopolymer content, biosolids conditioner requirement, and biosolids dewaterability. The benefit of the TAD system's higher solids reduction capability is offset by poor effluent dewatering properties.

Table 2: Solution biopolymer and biosolids dewatering characteristics

\begin{tabular}{|c|c|c|}
\hline & $\begin{array}{c}\text { Thermophilic } \\
\text { biosolids }\end{array}$ & $\begin{array}{c}\text { Mesophilic } \\
\text { biosolids }\end{array}$ \\
\hline $\begin{array}{c}\text { Solution biopolymer } \\
(\mathrm{mg} / \mathrm{L})\end{array}$ & $406.5 \pm 85.7$ & $139.4 \pm 33.8$ \\
\hline $\begin{array}{c}\text { Optimum cationic } \\
\text { polymer dose* } \\
\text { (mL/mL sludge) }\end{array}$ & $8.3 \pm 0.6$ & $5.0 \pm 1.7$ \\
\hline Raw CST (sec, avg) & $4169.8 \pm 351.3$ & $292.4 \pm 91.6$ \\
\hline
\end{tabular}

* Cationic polymer ( $1 \% \mathrm{w} / \mathrm{w}$ Clarifloc) was used for the conditioning of biosolids.

\subsection{Sulfur based Odors from Dewatered Biosolids}

Dewatered thermophilic biosolids generated about 55 times greater peak organic sulfur compounds than dewatered mesophilic biosolids although the TAD system removed about $10 \%$ greater VS than the MAD system (Table 3). Also, the peak volatile sulfur compounds from TAD appeared at a much later incubation time than from MAD. Methanogens in the dewatered thermophilic biosolids might have needed a long acclimation time compared to ones in the dewatered mesophilic biosolids, which started to reduce sulfur-based odors in less than 10 days. It indicates that different methanogenic groups were predominant in dewatered biosolids from different digestion temperatures.

Table 3: Dewatered biosolids odors

\begin{tabular}{|c|c|c|}
\hline & $\begin{array}{c}\text { Dewatered } \\
\text { thermophilic } \\
\text { biosolids }\end{array}$ & $\begin{array}{c}\text { Dewatered } \\
\text { mesophilic } \\
\text { biosolids }\end{array}$ \\
\hline $\begin{array}{c}\text { Peak tVOSC } \\
(\text { ppmv as S/g VS) }\end{array}$ & $293.2 \pm 63.1$ & $5.3 \pm 3.1$ \\
\hline $\begin{array}{c}\text { Time to peak } \\
\text { tVOSC (days) }\end{array}$ & 32 to 38 & 1 to 10 \\
\hline
\end{tabular}

\subsection{Microbial Identity}

Out of 165 successful clones, 24 methanogens were identified by BLAST. All the identified DNA sequences showed $99 \%$ or more similarity to the known sequences in the BLAST database. Both primer sets generated the same OTUs (Table 4). Most identified methanogens in the thermophilic biosolids were hydrogenotrophic methanogens that generate methane from hydrogen and carbon dioxide. The rests were methylotrophic and aceticlastic methanogens that are capable of organic sulfur degradation.

Table 4: Identities of OTUs

\begin{tabular}{|c|c|c|}
\hline $\begin{array}{c}\text { Methanogenic } \\
\text { species }\end{array}$ & $\begin{array}{c}\text { \# of } \\
\text { copies }\end{array}$ & Identified OTUs* $^{*}$ \\
\hline Hydrogenotrophic & 9 & $\begin{array}{c}\text { Methanothermobacter } \\
\text { thermautotrophicus }\end{array}$ \\
\hline Methylotrophic & 1 & Methanomethylovorans \\
\hline Methylotrophic & 1 & Methanococcoides \\
\hline Aceticlastic & 1 & $\begin{array}{c}\text { Methanosarcina } \\
\text { acetivorans }\end{array}$ \\
\hline
\end{tabular}

* $99 \%$ or greater similarity to the known DNA sequences in BLAST. 
Jongmin Kim, Int. Ann. Sci.; Vol. 10, Issue 1, pp: 60-66, 2021

The overall VOSC generation mechanism is proposed in Fig. 2. Each step is marked and incorporated with the following discussion.

Considering a major component of the organic solids in sludge is a biopolymer [15], greater VS reduction would result in less proteinaceous materials in biosolids. However, tVOSC generated from the dewatered thermophilic biosolids was much greater than the dewatered mesophilic biosolids. It implies that the amount of sulfur-containing amino acids may not be the only factor that caused high organic sulfur compounds from thermophilically digested and dewatered biosolids (Step (a) and (b) in Fig. 2).

It was thought that elevated temperature and high sulfur environment retarded methanogen population in thermophilic biosolids thus resulting in low VOSC degradation from the dewatered thermophilic biosolids (Step (c) in Fig. 2). The same was also reported by many previous studies. Aceticlastic or methylotrophic methanogens have been observed to be able to degrade organic sulfur compounds from dewatered biosolids [3]. However, their metabolism was greatly suppressed under thermophilic digestion conditions [16] and even greater suppression on their metabolism was reported when the thermophilic anaerobic digester contains high sulfur [17]. While thermophilic sludge did not contain the right methanogen population as evidenced by clone library results (Table 4), high sulfur condition seemed to have accelerated the generation of VOSCs from dewatered biosolids (Step (d) in Fig. 2). Since organic sulfur can be also produced by methylation of sulfur and effluents of pulp and paper industries could supply sufficient sulfate and methylated aromatic compounds such as lignin, favorable condition for high organic sulfur production could be formed during the incubation of dewatered thermophilic biosolids. One study found that hydrogenotrophic methanogens were the major archaeal species at elevated temperature conditions and it also supports the observation of this study [18]. On the other hand, mesophilic sludge digestion condition accelerated methanogenic metabolism on organic sulfur compounds, which resulted in high organic sulfur degradation from dewatered mesophilic biosolids cakes.

The test results indicate that the advanced anaerobic digestion system like the temperature phased anaerobic digestion system (TPAD) can benefit from both higher solids removal from the first stage thermophilic system and greater VOSC removal in the second stage mesophilic anaerobic system. However, TPAD was reported to produce poor quality biosolids [19].

The intensity of shear during the biosolids dewatering process is another approach to understand the strength of odors from dewatered biosolids cakes [20]. Other than the biological odor generation and removal pathway, the sheer force imparted to the biosolids during dewatering can worsen sulfur-based odors and this may be worth to be considered when mitigating odor problems in the wastewater treatment plant with the anaerobic digestion system. Therefore, sludge odor problems may not be solved by looking into one stabilizing process, but a comprehensive approach is more appropriate to provide tangible solutions. [21]

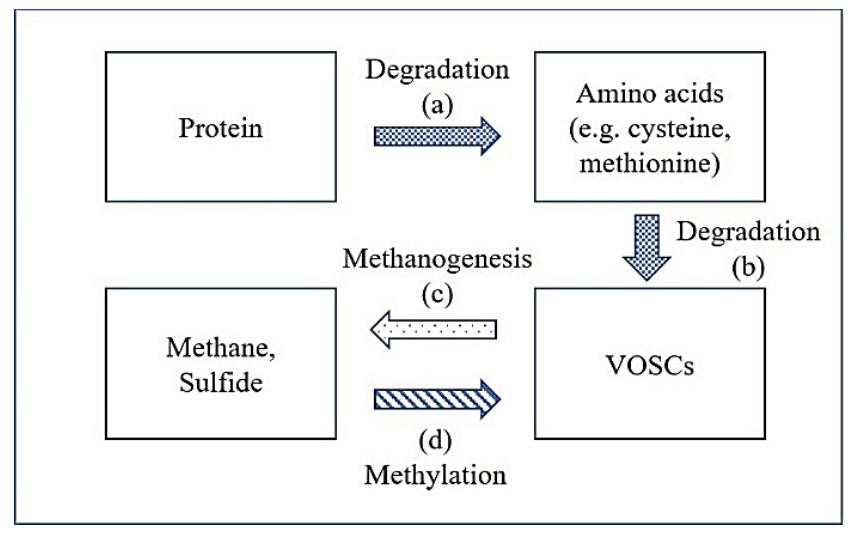

Figure 2: Proposed mechanism for high organic sulfur generation from dewatered thermophilic biosolids

\section{Conclusions}

This study focused on the mechanism of odorous volatile sulfur compounds generation and removal from dewatered biosolids from different anaerobic digestion temperatures. Despite greater solids reduction in the thermophilic anaerobic digestion system, much less sulfur odors were measured from the dewatered biosolids from the mesophilic digestion system. In other words, greater solids removal in the sludge treatment 
system does not always ensure less odor generation from the dewatered biosolids. Other conditions like high sulfur contents in the influents and different composition of archaeal species impacted more of the different odor generation patterns of the dewatered biosolids. It was found that methanogens that use hydrogen for the methane generation were prevalent in the thermophilically digested sludge and they were not capable of metabolizing methylated sulfur compounds. On the other hand, mesophilically biosolids cakes did not produce sulfur-based odors as much as thermophilic biosolids cakes did due to the early acclimation of methylotrophic methanogens to the incubation environment. Taking into consideration of the thermophilic system's greater solids removal capability and the mesophilic system's dewatered sludge odor control capability, TPAD can provide benefits of both temperature systems if its intrinsic poor sludge problem can be mitigated. Given that one stabilization process may also cause unforeseen adverse impacts on the sludge odor problems or other process difficulties, a comprehensive approach may be more appropriate to formulate tangible solutions.

\section{Declarations}

\subsection{Acknowledgements}

The author thanks to Dr. John T. Novak from Virginia Tech for supporting this study.

\subsection{Competing Interests}

The author declared that no conflict of interest exists in this publication.

\section{How to Cite this Article:}

Jongmin Kim, "Mechanism of Organic Odor Generation from Thermophilically Digested Biosolids", Int. Ann. Sci., vol. 10, no. 1, pp. 60-66, Sep. 2020. https://doi.org/10.21467/ias.10.1.60-66

\section{References}

[1] H. Byliński, R. J. Barczak, J. Gębicki, and J. Namieśnik, "Monitoring of odors emitted from stabilized dewatered sludge subjected to aging using proton transfer reactionmass spectrometry", Environ. Sci. Pollut. Res., no. 26, pp. 5500-5513. Jan. 2019. https://doi.org/10.1007/s11356-018-4041-4

[2] Z. K. Erdal, R. H. Forbes, J. Witherspoon, G. Adams, R. Hargreaves, R. Morton, J. T. Novak, and M. J. Higgins, "Recent Findings on Biosolids Cake Odor Reduction -
Results of WERF Phase 3 Biosolids Odor Research", $J$. Environ. Sci. Health A, vol. 43, no. 13, pp. 1575-1580. Dec. 2008. https://doi.org/10.1080/10934520802293792

[3] M. J. Higgins, Y. C. Chen, D. P. Yarosz, S. N. Murthy, N. A. Mass, D. Glindemann, and J. T. Novak, "Cycling of Volatile Organic Sulfur Compounds in Anaerobically Digested Biosolids and its Implication for Odors", Wate r Environ. Res., vol. 78, no. 3, pp. 243-252. Mar. 2006. http://doi.org/ 10.2175/106143005X90065

[4] C. D. Muller, N. Verma, M. J. Higgins, and J. T. Novak, "The role of shear in the generation of nuisance odors $\mathrm{fr}$ om dewatered biosolids", Proc. WEFTEC 2004, New O rleans, LA. Oct. 2004.

[5] B. Ren, Y, Zhao, N, Lyczko, and A. Nzihou, "Current Status and Outlook of Odor Removal Technologies in Wastewater Treatment Plant", Waste Biomass Valori., no. 10 , pp. 1443-1458. Jun. 2019. https://doi.org/10.1007/s12649-018-0384-9

[6] J. D. Zahler, R. H. Bucher, J. F. Ferguson, and H. D. Ste nse, "Performance and Stability of Two-Stage Anaerobi c Digestion", Water Environ. Res., vol. 79, no. 5, pp. 48 8-497. May. 2007. http://doi.org/ 10.2175/106143006X1 23157

[7] J. Kim, and J. T. Novak, "Digestion Performance of Various Combinations of Thermophilic and Mesophilic Sludge Digestion Systems", Water Environ. Res., vol. 83, no. 1, pp 44-52. Jan. 2011. https://doi.org/10.2175/106143010X12681059117337

[8] B. P. Lomans, C. Drift, A. Pol, and H. J. M. Camp, "Mi crobial cycling of volatile organic sulfur compounds", $C$ ell. Mol. Life Sci, vol. 59, pp. 575-588. Apr. 2002. https: //doi.org/10.1007/s00018-002-8450-6

[9] American Public Health Association (APHA) "Standard Methods for Examination of Water and Wastewater", 2 0th edn. APHA, AWWA, WPCF, Washington, DC. 199 8

[10] D. Glindemann, S. N. Murthy, M. J. Higgins, Y. C. Che $\mathrm{n}$, and J. T. Novak, "Biosolids incubation method for od orous gas measurement from dewatered sludge cakes", $J$ our. Residuals. Sci \& Tech., vol. 3, no. 3, pp. 153-160. J ul. 2006. https://pennstate.pure.elsevier.com/en/publicat ions/biosolids-incubation-method-for-odorous-gas-meas urement-from-dewa

[11] L. Ovreas, L. Forney, F. L. Daae, and V. Torsvik, "Distribution of bacterioplankton in meromictic Lake Saelenvannet, as determined by denaturing gradient gel electrophoresis of PCR-amplified gene fragments coding for 16S rRNA", Appl. Environ. Microbiol., vol. 63, no. 9, pp. 3367-3373. Sept. 1997. https://pubmed.ncbi.nlm.nih.gov/9292986/

[12] G. Muyzer, E. C. Dewaal, and A. G. Uitterlinden, "Profiling of Complex Microbial-Populations by Denaturing Gradient Gel-Electrophoresis Analysis of Polymerase Chain Reaction-Amplified Genes-Coding for 16s Ribosomal-RNA", Appl. Environ. Microbiol., vol. 59, no. 3, pp. 695-700. Mar. 1993. https://pubmed.ncbi.nlm.nih.gov/7683183/

[13] S. F. Altschul, W. Gish, W. Miller, E. W. Myers, and D. J. Lipman, "Basic local alignment search tool", J. Mol. Biol., vol. 215, no. 3, pp. 403-10, Oct. 1990. https://doi.org/10.1016/S0022-2836(05)80360-2

[14] J. T. Novak, and C. Park, "Chemical conditioning of slu dge", Water sci. Technol., vol. 49, no. 10, pp. 73-80. M ay. 2004. http://doi.org/10.2166/wst.2004.0612

[15] B. Forbes, G. Adams, J. Witherspoon, D. McEwen, Z. E rdal, L. Hentz, S. N. Murthy, T. Card, D. Glindemann, and M. J. Higgins, "Impacts of the In-Plant Operational 
Jongmin Kim, Int. Ann. Sci.; Vol. 10, Issue 1, pp: 60-66, 2021

Parameters on Biosolids Odor Quality - Final Results of WERF Odor Project Phase 2 Field and Laboratory Study", Proc. WEF/A\&WMA Odors and Air Emissions 2004, Bellevue, WA, Apr. 2004.

[16] A. C. Wilson, "Mechanisms of methanogenic inhibition in advanced anaerobic digestion", Ph.D. dissertation for Virginia Polytechnic Institute and State University, 2009

[17] S.A. Freeman, R. Sierra-Alveraz, M. Altinbas, J. Hollin gsworth, A. J. M. Stams, and H. Smidt, "Molecular char acterization of mesophilic and thermophilic sulfate redu cing microbial communities in expanded granular sludg e bed (EGSB) reactors", Biodeg., vol. 19, no. 2, pp. 161177. Apr. 2008. http://doi.org/10.1007/s10532-007-9123 $-9$

[18] F. Bu, N. Dong, S. K. Khanal, L. Xie, and Q. Zhou, "Eff ects of $\mathrm{CO}$ on hydrogenotrophic methanogenesis under $\mathrm{t}$ hermophilic and extreme-thermophilic conditions: Micr obial community and biomethanation pathways", Biores ource Technol., vol. 266, pp. 364-373. Oct. 2018. http:// doi.org/10.1016/j.biortech.2018.03.092

[19] J.L. Bivins, and J. T. Novak, "Changes in dewatering properties between the thermophilic and mesophilic stages in temperature phased anaerobic digestion systems", Water Environ. Res., vol 73, no. 4, pp. 444-449. Jul. 2001. https://doi.org/10.2307/25045520

[20] D. Zhang, M. Strawn, T. Broderick, J.T. Novak, and Z. W. Wang, "Effects of anaerobic digester solids retention time on odor emission and dewaterability of biosolids $\mathrm{s}$ ubjected to various shear intensities, polymer doses, and storage duration times", Environ. Sci.: Water Res. Tech nol., no. 6, pp. 1588-1596. Mar. 2020. https://doi.org/10 .1039/D0EW00028K

[21] R. M. Fisher, J. P. Alvarez-Gaitan, and R. M. Stuetz, "R eview of the effects of wastewater biosolids stabilization processes on odor emissions", Crit. Rev. Environ. Sci. T echnol., vol. 49, no. 17, pp. 1515-1586. Mar. 2019. https://doi.org/10.1080/10643389.2019.1579620
Publish your research article in AIJR journalsOnline Submission and Tracking Peer-Reviewed

Rapid decision

Immediate Publication after acceptance

Articles freely available online

Retain full copyright of your article.

Submit your article at journals.aijr.in

Publish your books with AIJR publisherPublish with ISBN and DOI. Publish Thesis/Dissertation as Monograph

Publish Book Monograph.

Publish Edited Volume/ Book.

Publish Conference Proceedings Retain full copyright of your books. Submit your manuscript at books.aijr.org 